\title{
Management of Retinitis Pigmentosa via Platelet Rich Plasma or Combination with Electromagnetic Stimulation: Retrospective Analysis of One-year Results
}

Umut Arslan ( $\nabla$ drumutarslan@hotmail.com )

Ankara Universitesi https://orcid.org/0000-0003-4146-8083

Emin Özmert

Ankara Universitesi Tip Fakultesi

\section{Research}

Keywords: Retinitis pigmentosa, growth factors, platelet rich plasma, electromagnetic stimulation, iontophoresis

Posted Date: February 19th, 2020

DOl: https://doi.org/10.21203/rs.2.23921/v1

License: (c) (i) This work is licensed under a Creative Commons Attribution 4.0 International License.

Read Full License

Version of Record: A version of this preprint was published at Advances in Therapy on April 18th, 2020. See the published version at https://doi.org/10.1007/s12325-020-01308-y. 


\section{Abstract}

Purpose To investigate whether the natural progression rate of retinitis pigmentosa can be decreased with subtenon autologous platelet rich plasma application alone or combination with retinal electromagnetic stimulation.

Material and methods The study includes retrospective analysis of 60 retinitis pigmentosa patients. Patients constitute 3 groups with similar demographic characteristics. The combined management group consists of 20 retinitis pigmentosa patients (40 eyes) who received combined retinal electromagnetic stimulation and subtenon platelet rich plasma as Group1; The subtenon platelet rich plasma-only group consisted of 20 retinitis pigmentosa patients (40 eyes) as Group2; The natural course (control) group consists of 20 retinitis pigmentosa patients (40 eyes) who did not receive any treatment were classified as Group3. Horizontal and vertical ellipsoid zone width, fundus perimetry deviation index and best corrected visual acuity changes were compared within and between groups after one year follow up period.

Results Horizontal ellipsoid zone percentage changes were detected $+1 \%$ in Group1, $-2.85 \%$ in Group2, $-9.36 \%$ in Group3 ( $\Delta p 1>2>3)$. Vertical ellipsoid zone percentage changes were detected $+0.34 \%$ in Group1, $-3.05 \%$ in Group2, $-9.09 \%$ in Group3 $(\Delta p 1>2>3)$. Fundus perimetry deviation index percentage changes were detected $+0.05 \%$ in Group1, $-2.68 \%$ in Group2 and $-8.78 \%$ in Group3 ( $\Delta p 1>2>3)$.

Conclusion Platelet-rich plasma is a good source of growth factors, but its half-life is 4-6 months. Subtenon autologous platelet rich plasma might more effectively slow down photoreceptor loss when repeated as booster injections and combined with retinal electromagnetic stimulation.

\section{Introduction}

Retinitis pigmentosa (RP) is a progressive outer retinal degeneration resulting from mutation in any of the 260 genes found in the photoreceptor (PR) or retinal pigment epithelium (RPE) [1]. The progression rate and findings of the disease are heterogeneous according to genetic mutation and heredity type. The initial symptom of the disease is usually night blindness (nyctalopia) beginning in childhood or adolescence. Narrowing of the visual field and legal blindness develops as the disease progresses [2-4]. If low grade inflammation is added, then the disease is complicated by cataracts, an epiretinal membrane, and macular edema [5]. In the fundus examination, the appearance of midperipheral bone spicule pigmentation is usually sufficient to diagnosis [1]. Developments in spectral domain optical coherence tomography (SD-OCT) enable detailed imaging of the sensorial retina and the ellipsoid zone. Ellipsoid zone (EZ) is an OCT image of the inner and outer segments of photoreceptor cells. Loss of EZ is the gold standard in the diagnosis and follow-up of RP $[6,7]$. Visual field (VF) monitoring and electroretinography (ERG) are indirect signs of EZ loss and correlated with EZ width (EZW) [6]. Mutations in PR or RPE disrupt the synthesis of some vital peptides and growth factors for photoreceptors [1]. 
Autologous platelet-rich plasma (aPRP) is a good source of growth factors. Platelets have more than 30 growth factors and cytokines in a-granules. These peptides regulate the energy cycle at the cellular level. They also control local capillary blood flow, neurogenesis, and cellular metabolism [8, 9]. Subtenon aPRP application in the management of RP patients has been shown to be clinically effective [10].

Repetitive electromagnetic stimulation (rEMS) increases binding affinity and the synthesis of growth factor receptors on neural tissues [11-14]. It provides electromagnetic iontophoresis by changing the electrical charges of scleral pores and tyrosine kinase receptors (Trk) [15-17]. rEMS forms hyperpolarization-depolarization waves in neurons thereby increasing neurotransmission and capillary blood flow [18]. Trk receptors are commonly found around limbus, extraocular muscle insertions, and the optic nerve [19]. Molecules smaller than $75 \mathrm{kD}$ can passively move from the sclera to the suprachoroidal space. Electrical or electromagnetic iontophoresis is required for molecules larger than $75 \mathrm{kD}$ such as BDNF and IGF to pass through the sclera into the subretinal space [15-17]. The clinical efficacy of rEMS alone or in combination with subtenon aPRP has also been shown [11].

The aim of this study is to investigate whether the natural progression rate of RP can be decreased with subtenon aPRP application alone or combination with rEMS.

\section{Material And Methods}

The study includes retrospective analysis of $60 \mathrm{RP}$ patients who were followed up at Ankara University Faculty of Medicine between 2017 and 2019. Ethical committee approval was obtained from the Ankara University Faculty of Medicine Clinical Research Ethics Committee (19-1293-18). The study was carried out in accordance with the 2013 Helsinki Declaration.

The best corrected visual acuity (BCVA) was recorded as letters on the ETDRS chart (Topcon CC 100 XP, Japan). The ellipsoid zone width (EZW) shows healthy photoreceptors and was measured horizontally and vertically on cross-sectional structural SD-OCT (RTVue XR "Avanti", Optovue, Fremont, CA, USA). A manual segmentation program was used for the measurement of EZW. Fundus perimetry deviation index (FPDI) records were examined in the $24 / 2$ visual field of computerized perimetry records (Compass, CenterVue, Padova, Italy). The FPDI offers data explaining how many of the 100 flashing points can be seen correctly by the patient and what percentage of the visual field can be seen.

The total amount of $60 \mathrm{RP}$ patients constitute 3 groups with similar demographic characteristics:

Group 1: The combined management group consists of 20 RP patients (40 eyes) who received combined rEMS and aPRP. The rEMS was applied with a custom-designed helmet for 30 minutes just before the subtenon aPRP injection. These combined applications were repeated 3 times a month with a 2-week interval (loading dose). Then, two additional booster doses were applied with 6-month intervals. The course of the disease was evaluated by comparing the BCVA, EZW, and FDPI parameters recorded before the first application and within 3 months after the last application. 
Group 2: The aPRP-only group consisted of 20 RP patients (40 eyes) who received only subtenon aPRP injections. The aPRP applications were repeated 3 times a month with a 2-week interval (loading dose). Then, two additional booster doses were applied with 6-month intervals. The course of the disease was evaluated by comparing the BCVA, EZW, and FDPI parameters recorded before the first application and within 3 months after the last application.

Group 3: The natural course (control) group consists of 20 RP patients (40 eyes) who did not receive any treatment and were followed. The natural course of the disease was evaluated by comparing the BCVA, EZW, and FDPI parameters recorded at the beginning and at the end of the first year.

Preparation of autologous PRP and its application: $20 \mathrm{ml}$ of blood was taken from the antecubital veins of the patients. It was transferred sterile to two $10 \mathrm{ml}$ citrated PRP tubes (T-LAB PRP Kit, T-Biyoteknoloji, Bursa, Turkey). The plasma was separated in a refrigerated centrifuge (1200 NF Nüve, Nüve Technology Laboratory, Ankara, Turkey) $+4.0^{\circ} \mathrm{C}$ for $8 \mathrm{~min}$ at $2500 \mathrm{rpm}$ centrifugation. The bottom $1 / 3$ of the upper plasma was drawn into a $2.5 \mathrm{ml}$ sterile syringe as a section rich in growth factors. The $1.5 \mathrm{ml}$ PRP solution was then injected into the subtenon space under topical anesthesia. The injections were made under sterile conditions at the upper-temporal quadrant with a $26-\mathrm{G}$ needle tip.

Retinal repetitive electromagnetic stimulation (rEMS): The rEMS helmet (Magnovision ${ }^{\mathrm{TM}}$, Bioretina Biotechnology, Ankara, Turkey) stimulated the retina and visual pathways with an electromagnetic field strength of 2000 miligauss, frequency of 42 hertz, and duration 30 minutes. The field was applied just before the PRP application. These values were previously determined to be effective for other clinical and preclinical studies.

The primary outcome measurement are the horizontal and vertical ellipsoid zone widths-these directly show the structural changes in the photoreceptors. The secondary outcome measure is a change in micrometry FDPI values.

Statistical analysis of data: Descriptive statistics are presented with frequency, percentage, mean, and standard deviation values. A paired t-test was used to examine whether the pre and post measurement values are different within group. A Sidak binary comparison test examined the measurement difference between groups. An ANOVA test was performed to examine whether the groups are different by age. Here, $p$-values less than 0.05 were considered statistically significant $(a=0.05)$. Analyzes were made with SPSS 22.0 package program. The effect of interventional procedures on the natural course of retinitis pigmentosa was evaluated by comparing quantitative data from Group 1, 2, and 3 .

\section{Results}

The mean age was 33.0 (22-51 years) in Group 1, 32.6 (20-56 years) in Group 2, 31.7 (20-57 years) in Group 3. The mean follow-up time between the first measurements and the last measurements in all three groups was 13 months (12-15 months). There were no statistical differences between the groups in terms of age and follow-up times $(p=0.81)$. 
The mean horizontal ellipsoid zone width (m-HEZW): Group 1 was $3.46 \mathrm{~mm}$ before combined management and $3.50 \mathrm{~mm}$ after the procedures. During the mean 13-month follow-up, this positive change was $1.0 \%$ on average $(p=0.10)$. In Group 2 , the $\mathrm{m}$-HEZW was $3.32 \mathrm{~mm}$ at the first measurement and $3.26 \mathrm{~mm}$ after the PRP injections. During the mean 13-month follow-up, the change was found to be $-2.9 \%$ on average $(p=0.01)$. In Group 3 , the $\mathrm{m}$-HEZW was $3.32 \mathrm{~mm}$ at the initial examination and 3.03 $\mathrm{mm}$ at the last examination. Over the 13-month follow-up, this negative change was found to be $-9.4 \%$ on average $(p=0.01)$. Tables 1-4, Figures 1,2,5

The mean vertical ellipsoid zone width ( $\mathrm{m}$-VEZW): This value was $3.32 \mathrm{~mm}$ in Group 1 before the combined application and $3.33 \mathrm{~mm}$ after the procedures. During the mean 13-month follow-up, the change was $0.3 \%$ on average $(p=0.19)$. In Group 2 , the $m-V E Z W$ was $3.09 \mathrm{~mm}$ at the first measurement and $3.02 \mathrm{~mm}$ after PRP injections. The change was $-3.1 \%$ on average during the mean 13-month followup ( $p=0.01)$. In Group 3, the $\mathrm{m}$-VEZW was $3.27 \mathrm{~mm}$ at the initial examination and $2.97 \mathrm{~mm}$ at the last examination. The change was found to be $-9.1 \%$ on average during the mean 13-month follow-up ( $p=$ 0.01). Tables 1-4, Figures 6,9

The mean of the fundus perimetry deviation index (m-FDPI): This value was $43.45 \%$ in Group 1 before PRP combined with rEMS and $43.50 \%$ after the procedures. The mean change was $0.05 \%$ on average during the 13 -month follow-up ( $p=0.90)$. In Group 2, the m-FDPI was $46.13 \%$ at the first measurement and $43.45 \%$ after PRP injections. The change was $-2.68 \%$ on average during the mean 13 -month followup $(p=0.01)$. In Group 3, the $m-F D P I$ was $54.30 \%$ at the initial examination and $45.38 \%$ at the last examination. The change was

$-8.78 \%$ on average during the mean 13-month follow-up $(p=0.01)$.

Tables 1-4, Figures $3,4,7,8,10$

The mean best corrected visual acuity (m-BCVA): Group 1 could identify 91.6 letters before PRP combined with rEMS applications and 92.3 letters after the procedure. During the mean 13-month follow-up, the change was found to be an average of 0.7 letters $(p=0.08)$. Group 2 had a m-BCVA of 88.2 letters at baseline and 87.6 letters after PRP injections. The change was -0.6 letters on average $(p=0.07)$ during the mean 13-month follow-up. Group 3 had a m-BCVA score of 89.8 letters at the initial examination and 88.4 letters at the end. The change was found to be an average of -1.4 letters during the mean 13-month follow-up $(p=0.02)$.

When Groups 1, 2, and 3 were compared by the Sidak test according to the HEZW, VEZW, and FDPI changes, the combined application of rEMS and subtenon aPRP significantly increases the three assessment parameters. Table 4

\section{Discussion}

There are currently over 260 different genetic mutations known to cause retinitis pigmentosa. Genetic inheritance can be autosomal dominant (AD), autosomal recessive (AR), X-linked, mitochondrial, mosaicism, or sporadic patterns [1]. Thus, the prognosis is usually quite heterogeneous. Acquired factors such as nutrition, smoking, anemia, pregnancy, as well as long-term exposure to ultraviolet and blue light 
also affect the course of the disease[2-4]. Autosomal dominant inheritance shows the slowest progression with an average annual loss of $5 \%$ photoreceptors [20,21]. X-linked inheritance shows the fastest progression with an average annual loss of $15 \%$ of photoreceptors [21, 22].

Knowledge about which genetic mutation affects the progression is increasing due to widespread genetic testing. The annual progression rate of retinitis pigmentosa was reported to be $5 \%$ in $\mathrm{RHO}$ gene mutation that was inherited as AD, and 15\% in RPGR gene mutation inherited as X-linked [20-22]. The photoreceptors have cilia tubule functions that provide the transport of opsin and rhodopsin and can be impaired by X-linked mutations -they can be distinguished by the presence of widespread lipofuscin deposits in the fundus examination. The ciliopathy gene mutations have three-fold faster progression than non-ciliopathy mutations [23]. Retinitis pigmentosa progresses with an average of $10 \%$ annual photoreceptor loss when AD, AR, X-linked, and mitochondrial inheritance patterns are collectively evaluated $[6,24,25]$. In our study, the annual photoreceptor loss rate was found to be $9.3 \%$ on average in the RP group without interventional procedures (Group 3, natural course) similar to the literature.

The visual function begins with the photochemical conversion of light energy, which comes from the objects and focuses on the retina with conversion to electrical signals. Photochemical conversion occurs in the sensorial unit and microenvironment consisting of a choriocapillaris-retina pigment epitheliumphotoreceptor trio. The retina pigment epithelium is the unit center where the synthesized peptide growth factors (GFs) regulate photochemical reactions. These include the oxidative phosphorylation and energy cycle of glucose in the blood; transport of vitamin A, minerals, anions, cations, and necessary coenzymes; the synthesis of opsin-rhodopsin and necessary peptides in the visual cycle; and the removal of metabolic waste that occurs in RPE [26-29].

The growth factors, peptides, and fragments required for these functions are encoded by over 260 genes in RPE. Mutations in any of these genes leads to progressive vision loss and progressive degeneration of the sensorial unit [1]. In particular, mutations that affect the conversion of glucose to adenosine triphosphate (ATP) lead to a condition in photoreceptor cells called sleep mode or dormant phase [30, 31]. Cells in this state have more solid plasma-they are live but metabolically inactive[32]. The photoreceptors in the dormant phase can be metabolically reactive if neurotrophins and GFs can be delivered the microenvironment of the sensorial unit [33]. Neurotrophins and GFs are key molecules in the cellular energy cycle [34]. Prolonged dormant phase or conditions impairing sensorial unit homeostasis eventually lead to apoptosis and cell loss [33]. RPE forms the outer blood-retinal barrier with its tight connections. Defects in the external blood retinal barrier due to apoptosis disrupt the immune-protected state in the retina and lead to low-density inflammation in the sensory unit. Neuro-inflammation accelerates the apoptosis process and sensorial unit loss [5].

Platelet-rich plasma is a good source of growth factors. Platelets have more than 30 GFs and cytokines in a-granules such as neurotrophic growth factor (NGF), neural factor (NF), brain derived neurotrophic factor (BDNF), basic fibroblast growth factor (bFGF), insulin-like growth factor (IGF), transforming growth factor (TGF- $\beta$ ), vascular endothelial growth factor (VEGF), platelet derived growth factor (PDGF), etc. These 
peptides regulate the energy cycle at the cellular level, local capillary blood flow, neurogenesis, and cellular metabolism [8-10]. Anti-inflammatory effects of PRP are also associated with soluble cytokines [35].

Our previous clinical and prospective study showed that subtenon injection of aPRP significantly increased the visual functions $[10,11]$. Clinical and preclinical studies showed that the half-life of GFs in tissue derived from PRP is 4-6 months [36-38]. Our clinical observations are similar. Here, we investigated the effects of three loading doses with a 2-week interval and 2 boosters with 6 -month interval of subtenon aPRP injections on photoreceptor loss (measured by EZW on SD-OCT) during the one-year follow-up. The photoreceptor loss rates during the follow-up period were $9.3 \%$ in the natural course group (group 3) and $3 \%$ in the only aPRP group (group 2). These results suggest that subtenon aPRP injection can decrease the photoreceptor loss rate by approximately three-fold.

The growth factors applied into the subtenon region reach the suprachoroidal area through the scleral pores. GFs in the choroidal matrix reach the subretinal area through Trk receptors. Tyrosine kinase receptors are commonly found around the limbus, extraocular muscle insertions, and the optic nerve [19]. Molecules smaller than $75 \mathrm{kD}$ can pass through the sclera via passive transport to the suprachroidal space [17]. BDNF and IGF are key growth factors in PRP and are larger than 75 kD [9].

Repetitive electromagnetic stimulation increases the affinity and synthesis of Trk growth factor receptors on neural tissues [11-14]. rEMS also provides electromagnetic iontophoresis effect by changing the electrical charges of the scleral pores and the peptides. Electrical or electromagnetic iontophoresis accelerates passing the large molecules such as BDNF and IGF through the sclera [15-17]. rEMS creates hyperpolarization-depolarization waves in neurons, which increases neuro-transmission and capillary blood flow [18]. In Group 1, rEMS was applied along with aPRP, and we found the change in mean EZW rate to be $0.7 \%$ at the end of one-year versus baseline. This result suggests that rEMS increases the effects of aPRP. The combined use of rEMS and aPRP has synergistic effects to prevent photoreceptor loss and reactivate the photoreceptor cells in sleep (dormant) mode. The electromagnetic field used here is far below the safety limits set by the World Health Organization [39].

In our study, ellipsoid zone widths and FDPI ratios in visual field showed similar changes. This proves that the visual field is related to the number of photoreceptors. The visual field is a subjective test and can be influenced by many parameters such as refractive error, media opacity, illumination intensity, the patient's current attention, learning curve etc [40]. The visual field test gives indirect data about the number and functions of photoreceptors. EZW is an objective parameter in tracking the number of photoreceptors, it is not affected by subjective situations. We believe that EZW can be used for diagnosis and follow-up as a substitute for visual field and electroretinography in most cases. In our opinion, EZW should be the gold standard diagnostic-follow-up criterion for RP.

In contrast to the visual field, the central visual acuity is affected too late in RP. Apoptosis occurring in photoreceptors in the periphery leads to Müller cell hypertrophy and ectopic synaptogenesis in the central 19-degree area. Due to the paracrine effects of Müller cells, the cone cells are not affected by apoptosis 
for a long time. Consequently, BCVA can remain stable for a long time [41]. In our study, BCVA in all three groups did not change during an average of 13 months follow-up.

Local and systemic adverse events related to rEMS and/or aPRP were not detected during the one-year follow-up. Patients did not describe any uncomfortable condition except for temporary light sensitivity (which may last several days due to aPRP injection) and headache (which may last several hours due to rEMS application).

This retrospective clinical study has some limitations. The annual progression rate of retinitis pigmentosa varies depending on the type of genetic mutation. However, this issue was not analyzed here because the genetic mutation analysis of each patient could not be performed. Inflammatory findings were observed in some genetic mutation types of RP or in some stages of the disease. There were no measurements such as a laser flare meter regarding how aPRP or combined procedures affect the inflammatory response. The progression rate of each genetic type and the effects of interventional procedures on inflammation are additional research topics.

\section{Conclusion}

Retinitis pigmentosa is a neurodegenerative genetic disorder with progressive photoreceptor loss. In recent years, growth factor injections, stem cell applications, or gene therapy options have come into clinical use to slow or stop disease progression. Platelet-rich plasma is a good source of growth factors, but its half-life is 4-6 months. aPRP might more effectively slow down photoreceptor loss when repeated as booster injections and combined with retinal electromagnetic stimulation.

\section{Abbreviations}

aPRP

Autologous platelet rich plasma

BCVA

Best corrected visual acuity

BDNF

Brain derived neurotrophic factor

EZW

Ellipsoid zone width

ERG

Electroretinography

ETDRS

Early treatment of diabetic retinopathy study

FDPI

Fundus perimetry deviation index

GFs 
Growth factors

IGF

Insulin-like growth factor

$\mathrm{kD}$

Kilo dalton

NGF

Neural growth factor

OCTA

Optical coherence tomography angiography

PRP

Platelet rich plasma

rEMS

Retinal electromagnetic stimulation

$\mathrm{RP}$

Retinitis pigmentosa

RPE

Retinal pigment epithelium

Trk

Tyrosine kinase

VF

Visual field

\section{Declarations}

Acknowledgements. We thank the participants of the study. We thank Prof.Dr Figen ŞERMET and the staff members of Ankara University Faculty of Medicine, Department of Ophthalmology.

Funding. No funding or sponsorship was received for this study. All authors had full access to all of the data in this study and take complete responsibility for the integrity of the data and accuracy of the data analysis.

Authorship. All named authors meet the International Committee of Medical Journal Editors (ICMJE) criteria for authorship for this article, take responsibility for the integrity of the work as a whole, and have given their approval for this version to be published.

Medical Writing Assistance. Medical writing and editorial assistance was provided by Ali Hariri from the American Manuscript Editors Company, which was funded by the authors.

Compliance with Ethics Guidelines. Ethical committee approval was obtained from the Ankara University Faculty of Medicine Clinical Research Ethics Committee (19-1293-18). The study was carried out in accordance with the 2013 Helsinki Declaration. 
Consent for publication. Not applicable.

Competing Interests. The authors declare that they have no competing interests.

Authors' contributions. UA and EÖ participated in the design of the study. UA carried out the analytical assays and performed the statistical analysis. UA drafted the manuscript. EÖ revised and approved the final manuscript. All authors read and approved the final manuscript.

Data Availability. The datasets generated during and/or analysed during the study are available from the corresponding author on reasonable request.

\section{Contributor Information.}

Umut Arslan, Email: bioretina.net@gmail.com

Emin Özmert, Email: eozmert56@gmail.com

\section{References}

1. Ali MU, Rahman MSU, Cao J, Yuan PX. Genetic characterization and disease mechanism of retinitis pigmentosa; current scenario. 3 Biotech. 2017; 7(4):251 2.

2. Wang AL, Knight DK, Vu TT, Mehta MC. Retinitis Pigmentosa: Review of Current Treatment. Int Ophthalmol Clin. 2019;59:263-280. doi: 10.1097/II0.0000000000000256.

3. Zhang Q. Retinitis Pigmentosa. Asia-Pacific Journal of Ophthalmology 2016; 265-271. doi:10.1097/apo.0000000000000227

4. Hartong DT, Berson EL, Dryja TP. Retinitis pigmentosa. The Lancet 2006; 1795-1809. doi:10.1016/s0140-6736(06)69740-7

5. Yoshida N, Ikeda Y, Notomi S, Ishikawa K, Murakami Y,et al. Clinical evidence of sustained chronic inflammatory reaction in retinitis pigmentosa Ophthalmology. 2013;120:100-5. doi: 10.1016/j.ophtha.2012.07.006.

6. Poornachandra B, Khurana AK, Sridharan P, Chatterjee P, Jayadev C, Yadav NK, Shetty R. Quantifying microstructural changes in retinitis pigmentosa using spectral domain - optical coherence tomography. Eye Vis (Lond). 2019 15;6:13. doi: 10.1186/s40662-019-0139-0.

7. Lima LH, Sallum JM, Spaide RF. Outer retina analysis by optical coherence tomography in cone-rod dystrophy patients. Retina. 2013;33:1877-80. doi: 10.1097/IAE.0b013e31829234e6.

8. Anitua E, Muruzabal F, Tayebba A, Riestra A, Perez VL, et al. Autologous serum and plasma rich in growth factors in ophthalmology: preclinical and clinical studies. Acta Ophthalmol. 2015;93(8):e605-e614

9. Amable PR, Carias RB, Teixeira MV, da Cruz Pacheco I, Corrêa do Amaral RJ, et al. Platelet-rich plasma preparation for regenerative medicine: optimization and quantification of cytokines and growth factors. Stem Cell Res Ther 2013; 4(3):67 
10. Arslan U, Özmert E, Demirel S, Örnek F, Şermet F. Effects of subtenon-injected autologous plateletrich plasma on visual functions in eyes with retinitis pigmentosa: preliminary clinical results. Graefe's Archive for Clinical and Experimental Ophthalmology 2018; 256(5), 893-908. doi:10.1007/s00417018-3953-5

11. Özmert E, Arslan U. Management of Deep Retinal Capillary Ischemia by Electromagnetic Stimulation and Platelet-Rich Plasma: Preliminary Clinical Results. Advances in Therapy 2019; doi:10.1007/s12325-019-01040-2

12. Maziarz A, Kocan B, Bester M. et al. How electromagnetic fields can influence adult stem cells: positive and negative impacts. Stem Cell Res Ther 2016; 7, 54. doi:10.1186/s13287-016-0312-5

13. Parate $D$, Kadir ND, Celik $C$. et al. Pulsed electromagnetic fields potentiate the paracrine function of mesenchymal stem cells. Stem Cell Res Ther 2020; 11, 46. doi:10.1186/s13287-020-1566-5

14. Patruno A, Ferrone A, Costantini E, Franceschelli S, Pesce M, et.al. Extremely low-frequency electromagnetic fields accelerates wound healing modulating MMP-9 and inflammatory cytokines. Cell Proliferation 2018; 51(2), e12432. doi:10.1111/cpr.12432

15. Demetriades AM, Deering T, Liu H, et al. Transscleral delivery of antiangiogenic proteins. J Ocul Pharmacol Ther. 2008;24(1):70-9. doi: 10.1089/jop.2007.0061.

16. Meng T, Kulkarni V, Simmers R, Brar V, Xu Q. Therapeutic implications of nanomedicine for ocular drug delivery. Drug Discov Today doi:10.1016/j.drudis.2019.05.00.

17. Li SK, Hao J. Transscleral passive and iontophoretic transport: theory and analysis. Expert Opin Drug Deliv. 2017;15(3):283-99. doi:10.1080/17425247.2018.1406918.

18. Luo J, Zheng H, Zhang L, Zhang Q, Li L, Pei Z, Hu X. High-frequency repetitive transcranial magnetic stimulation (rTMS) improves functional recovery by enhancing neurogenesis and activating BDNF/TrkB signaling in ischemic rats. International Journal of Molecular Sciences.2017; 18(2), 455. doi:10.3390/ijms18020455

19. Mysona BA, Zhao J, Bollinger KE. Role of BDNF/ TrkB pathway in the visual system: therapeutic implications for glaucoma. Expert Rev Ophthalmol. 2017;12(1):69-81.

20. Takahashi VKL, Takiuti JT, Carvalho-Jr JRL, Xu CL, Duong JK, Mahajan VB, Tsang SH. Fundus autofluorescence and ellipsoid zone (EZ) line width can be an outcome measurement in RHOassociated autosomal dominant retinitis pigmentosa. Graefes Arch Clin Exp Ophthalmol. 2019;257:725-731. doi: 10.1007/s00417-018-04234-6. Epub 2019 Jan 11.

21. Cai CX, Locke KG, Ramachandran R, Birch DG, Hood DC. A comparison of progressive loss of the ellipsoid zone (EZ) band in autosomal dominant and $x$-linked retinitis pigmentosa. Invest Ophthalmol Vis Sci. 2014 23;55:7417-22. doi: 10.1167/iovs.14-15013.

22. Sandberg MA, Rosner B, Weigel-DiFranco C, Dryja TP, Berson EL. Disease course of patients with Xlinked retinitis pigmentosa due to RPGR gene mutations. Invest Ophthalmol Vis Sci. 2007;48:1298304.

23. Takahashi VKL, Xu CL, Takiuti JT, Apatoff MBL, Duong JK, Mahajan VB, Tsang SH. Comparison of structural progression between ciliopathy and non-ciliopathy associated with autosomal recessive 
retinitis pigmentosa. Orphanet J Rare Dis. 2019;14:187. doi: 10.1186/s13023-019-1163-9.

24. Friberg TR. Natural course of retinitis pigmentosa over a three-year interval. Am J Ophthalmol. 1985 Oct 15;100(4):621-2.

25. Birch DG1, Anderson JL, Fish GE. Yearly rates of rod and cone functional loss in retinitis pigmentosa and cone-rod dystrophy. Ophthalmology. 1999;106:258-68.

26. Fuhrmann S, Zou CJ, Levine EM. Retinal pigment epithelium development, plasticity, and tissue homeostasis (Invited review for Experimental Eye Research). Exp Eye Res 2014; 0: 141-150. doi:10.1016/j.exer.2013.09.003.

27. Strauss 0. The Retinal Pigment Epithelium in Visual Function. Physiol Rev 2005; 85: 845-881, doi:10.1152/physrev.00021.2004

28. Cacares PS, Boulan ER. Retinal pigment epithelium polarity in health and blinding diseases. Current Opinion in Cell Biology 2020; 62:37-45

29. Dalvi S, Galloway CA, Singh R. Pluripotent Stem Cells to Model Degenerative Retinal Diseases: The RPE Perspective. Bharti K.(ed.) 2019, Pluripotent Stem Cells in Eye Disease Therapy, Advances in Experimental Medicine and Biology 1186, doi.org/10.1007/978-3-030-28471-8_Springer Nature Switzerland.

30. Collins MK, Perkins GR, Rodriguez-Tarduchy G, Nieto MA, López-Rivas A. Growth factors as survival factors: regulation of apoptosis. BioEssays 1994; 16(2):133-138 56.

31. Julian JL, Bauer DE, Kong M, Harris MH, Li C, Lindsten T, Thompson CB. Growth factor regulation of autophagy and cell survival in the absence of apoptosis. Cell 2005; 120(2):237-248

32. Munder MC, Midtvedt D, Franzmann T, Nüske E, Otto O, et al.A pH-driven transition of the cytoplasm from a fluid- to a solid-like state promotes entry into dormancy. eLife 5. 2016; pii: e09347

33. Koenekoop RK. Why some photoreceptors die,while others remain dormant: lessons from RPE65 and LRAT associated retinal dystrophies. Ophthalmic Genet 2011; 32:126-128 9.

34. Wang W, Lee SJ, Scott PA, Lu X, Emery D,et al. Two-step reactivation of dormant cones in retinitis pigmentosa. Cell Rep 2016; 15:372-385

35. Papait A, Cancedda R, Mastrogiacomo M, Poggi A. Allogeneic platelet-rich plasma affects monocyte differentiation to dendritic cells causing an anti-inflammatory microenvironment, putatively fostering wound healing. Tissue Eng Regen Med. 2018 ;12(1):30-43. doi: 10.1002/term.2361.

36. Reed GL, Fitzgerald ML, Polgár J. Molecular mechanisms of platelet exocytosis: insights into the $B$ secrete life of thrombocytes. Blood.2000; 96(10):3334-3342

37. Anitua E, Muruzabal F, Alcaldel, Merayo-Lloves J, Orive G. Plasma rich in growth factors (PRGFsEndoret) stimulates corneal wound healing and reduces haze formation after PRK surgery. Exp Eye Res.2013; 115:153-161

38. Limoli PG, Limoli C, Vingolo EM, Scalinci SZ, Nebbioso M. Cell surgery and growth factors in dry agerelated macular degeneration: visual prognosis and morphological study. Oncotarget.2016; 7(30):46913-46923 
39. Chandra T, Chavhan GB, Sze RW, Swenson E, Holowka S, Fricke W, Davidson S, lyer RS. Practical considerations for establishing and maintaining a magnetic resonance imaging safety program in a pediatric practice. Pediatric Radiology.2019; 49(4), 458-468. doi:10.1007/s00247-019-04359-8

40. Wu Z, Medeiros FA. Recent developments in visual field testing for glaucoma. Curr Opin Ophthalmol. 2018;29(2):141-146. doi: 10.1097/ICU.0000000000000461.

41. Michalakis S, Schäferhoff K, Spiwoks-Becker I, Zabouri N, Koch S, et al.Characterization of neurite outgrowth and ectopic synaptogenesis in response to photoreceptor dysfunction. Cell Mol Life Sci 2013; 70(10): 1831-1847

\section{Tables}

Due to technical limitations, Tables 1 - 4 are only available for download from the Supplementary Files section.

\section{Figures}




\section{Right / OD}
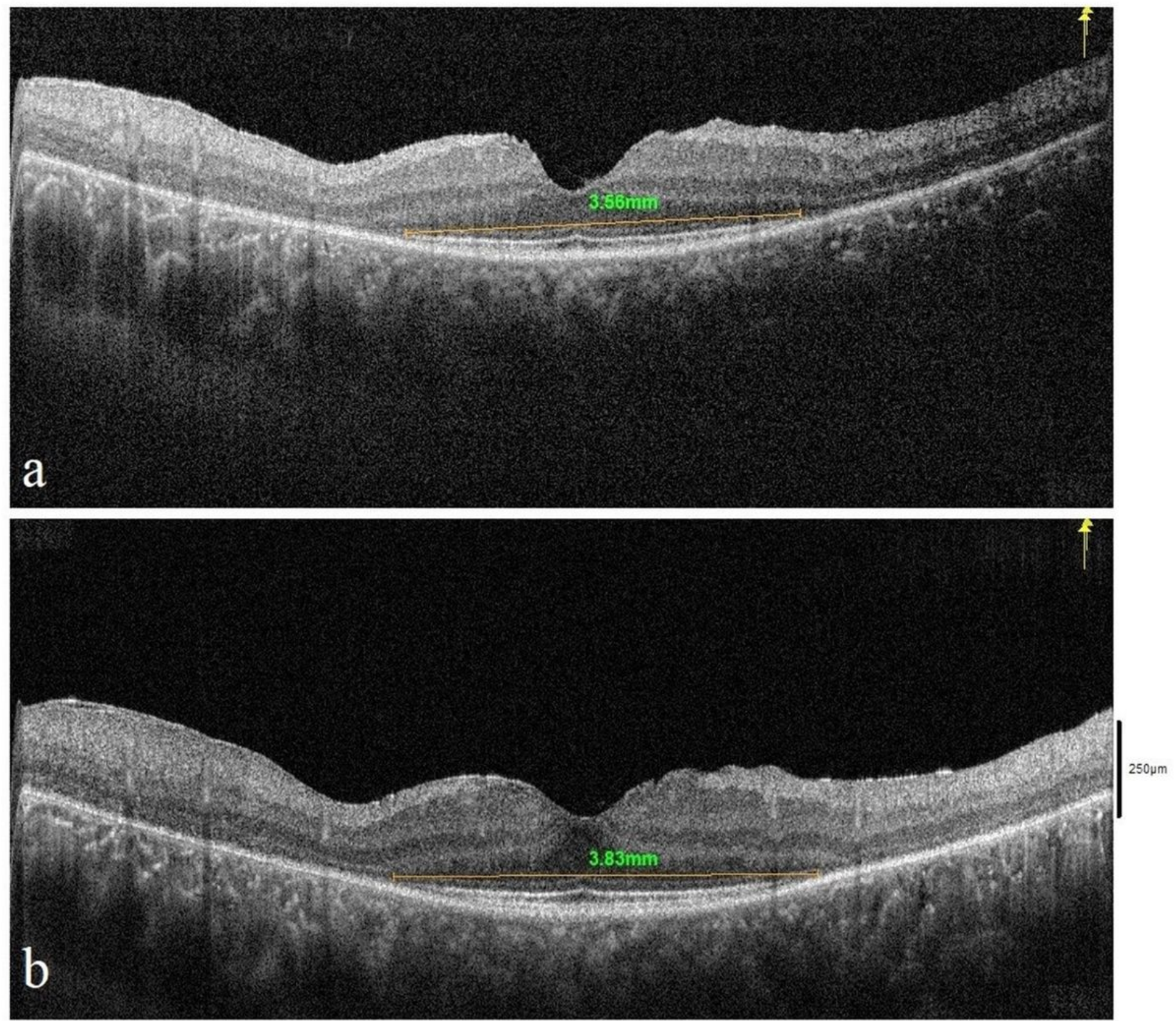

\section{Figure 1}

Horizontal EZWs of the retinitis pigmentosa patient receiving aPRP+ rEMS. (Table 1 Patient no 1). a: Before treatment: $3.56 \mathrm{~mm}$ b: The 13th month of follow-up post-treatment: $3.83 \mathrm{~mm}$. 


\section{Left / OS}
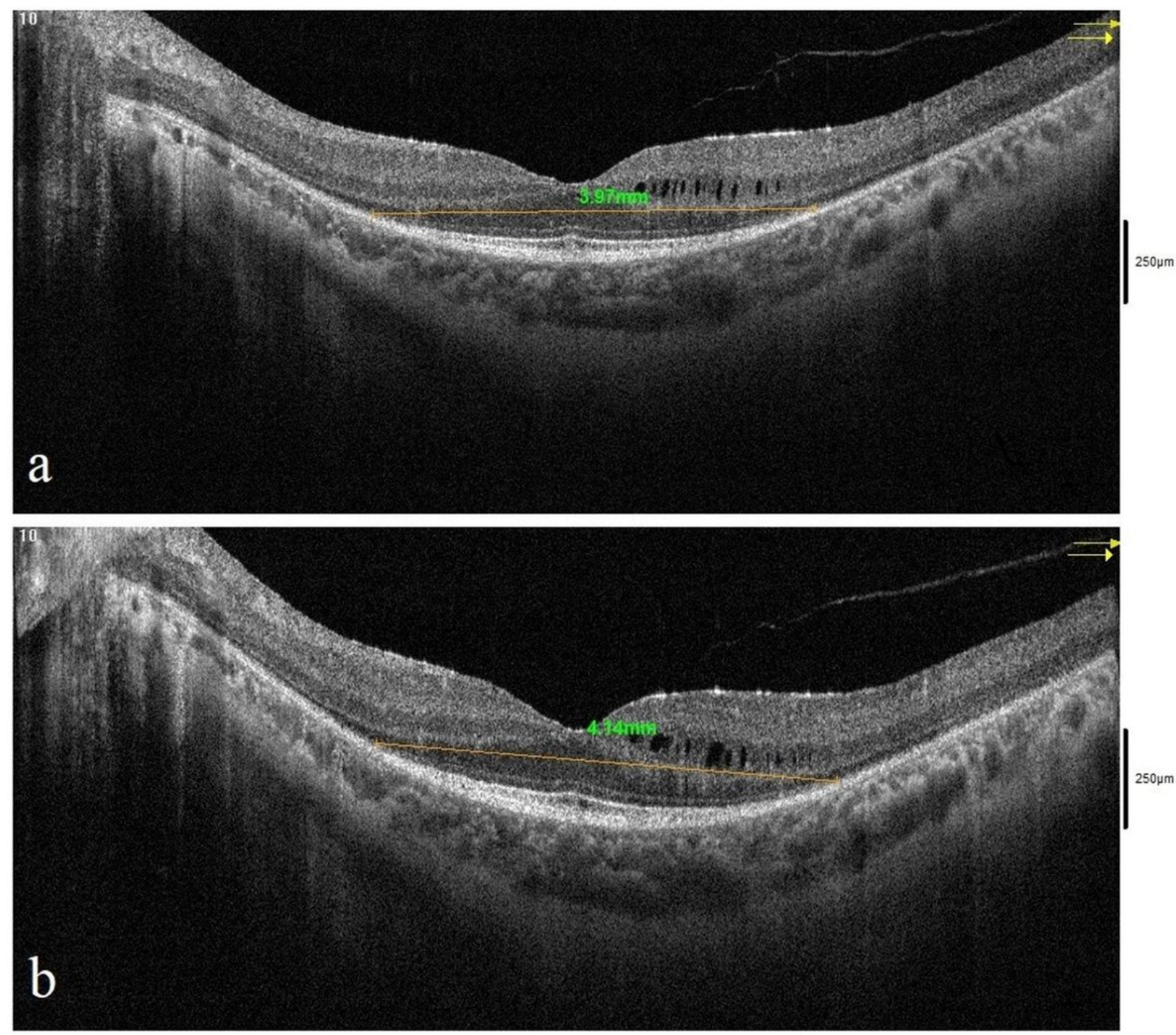

\section{Figure 2}

Horizontal EZWs of the retinitis pigmentosa patient receiving aPRP+ rEMS. (Table 1 Patient no. 2). a: Before treatment: $3.97 \mathrm{~mm}$ b: The 13th month of follow-up post-treatment: $4.14 \mathrm{~mm}$. 


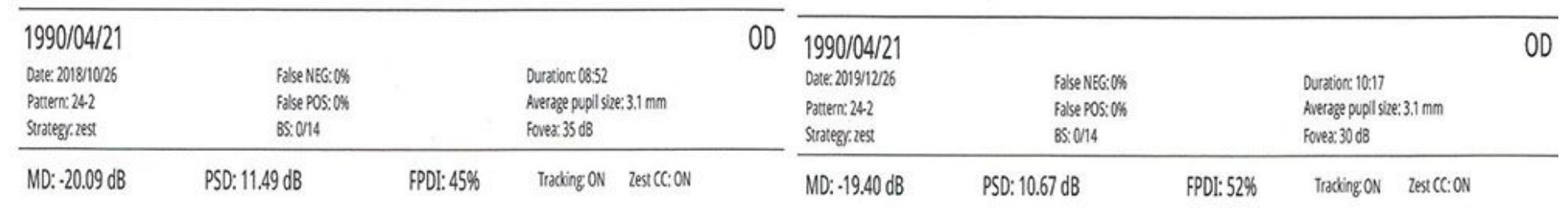
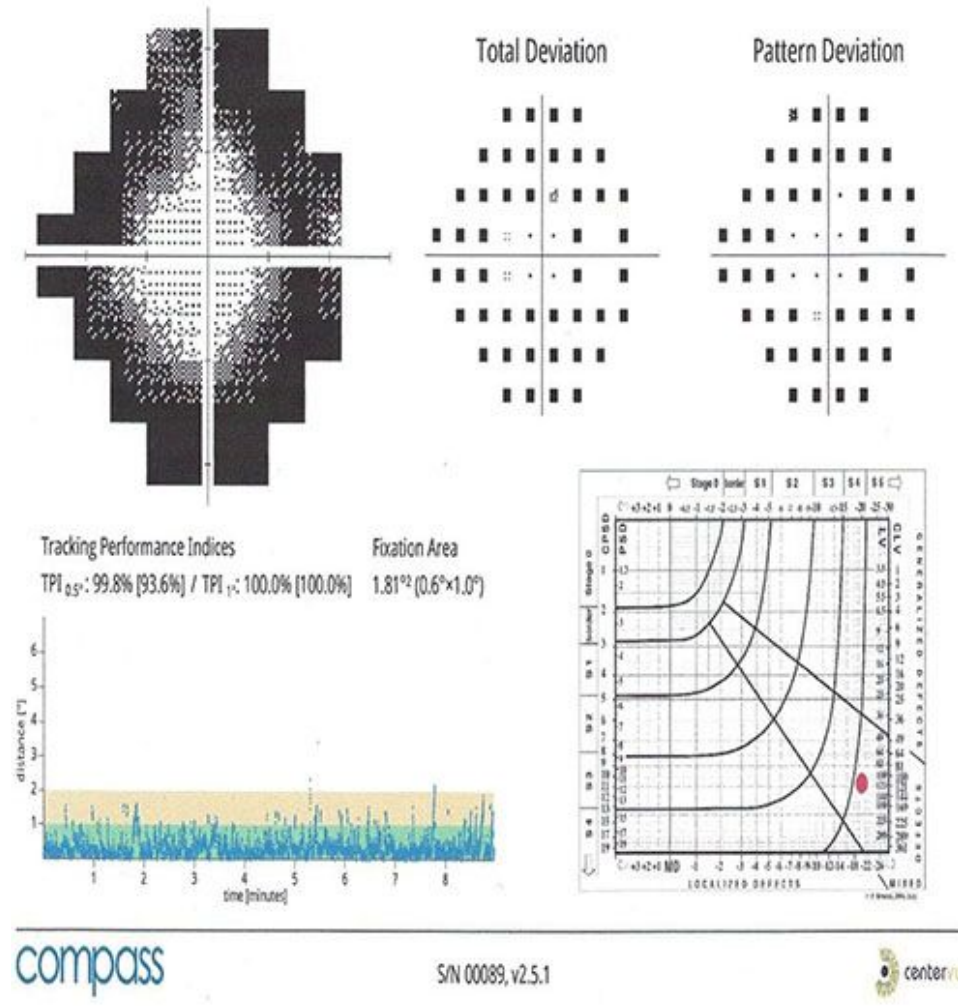

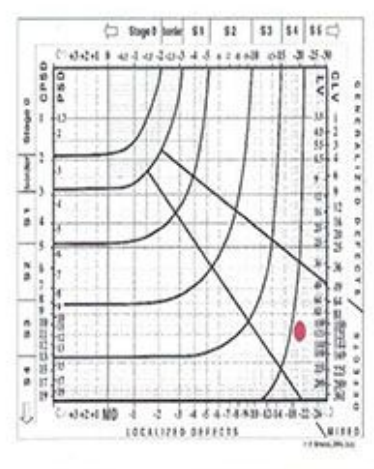

SN $000099,12.5 .1$
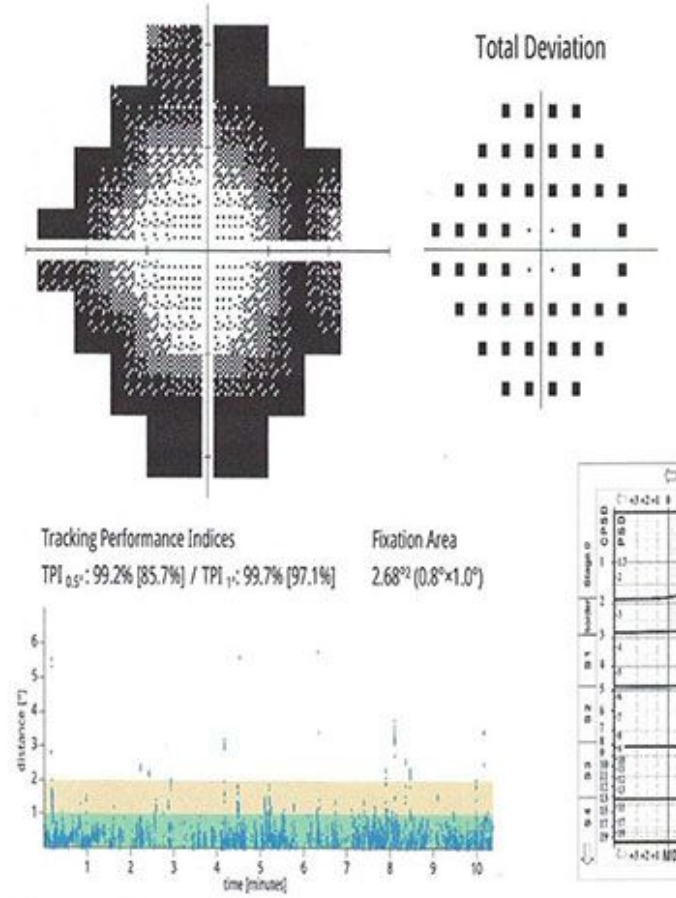

Pattern Deviation

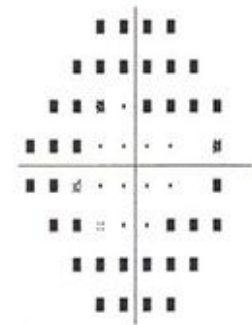

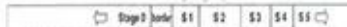

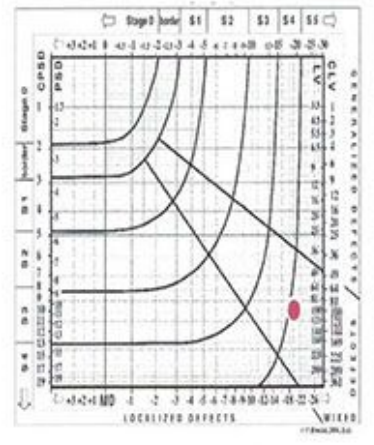

SN C00099, V2.5.1

\section{Figure 3}

Visual field FPDI changes of the retinitis pigmentosa patient receiving aPRP+ rEMS. (Table 1 Patient no. 1). a: Before treatment: $45 \%$ b: The 13 th month of follow-up post-treatment: $52 \%$ ). 


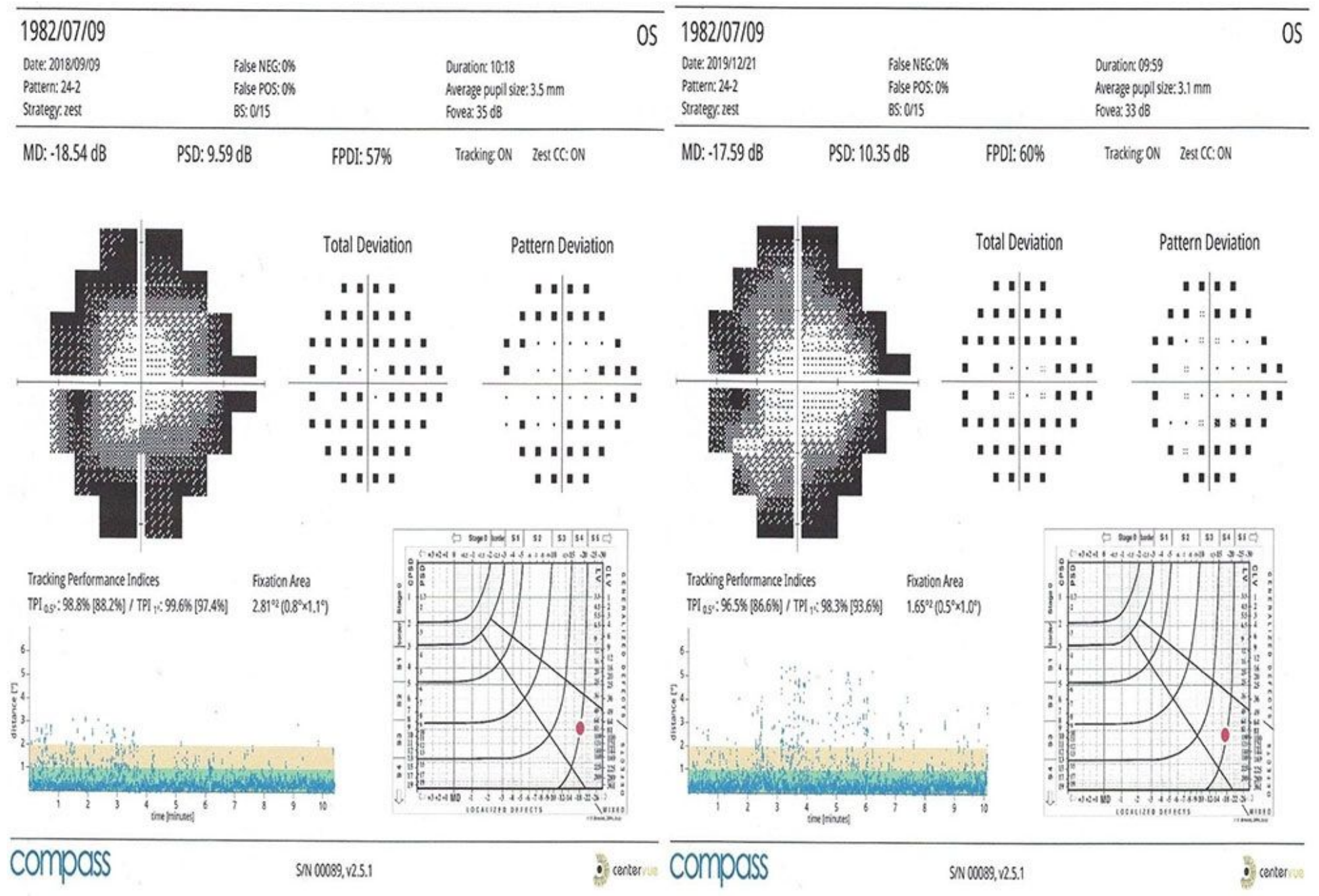

Figure 4

Visual field FPDI changes of the retinitis pigmentosa patient receiving aPRP+ rEMS. (Table 1 Patient no. 2). a: Before treatment: $57 \%$ b: The 13th month of follow-up post-treatment: $60 \%$. 


\section{Left / OS}
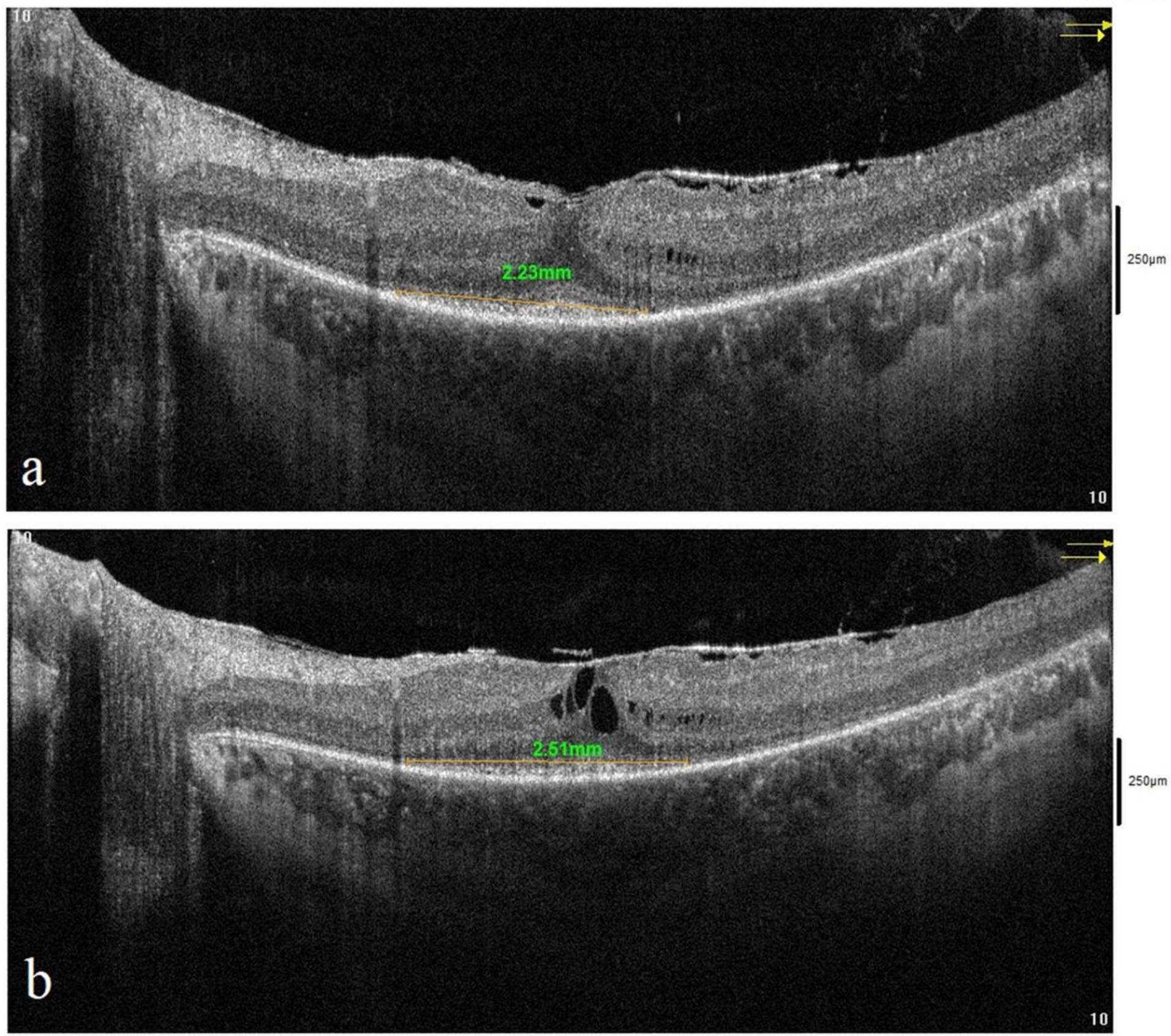

Figure 5

Horizontal EZWs of the retinitis pigmentosa patient receiving only aPRP. (Table 2 Patient no. 1). a: Before treatment: $2.23 \mathrm{~mm}$ b: The 13th month of follow-up post-treatment: $2.51 \mathrm{~mm}$. 
Right / OD
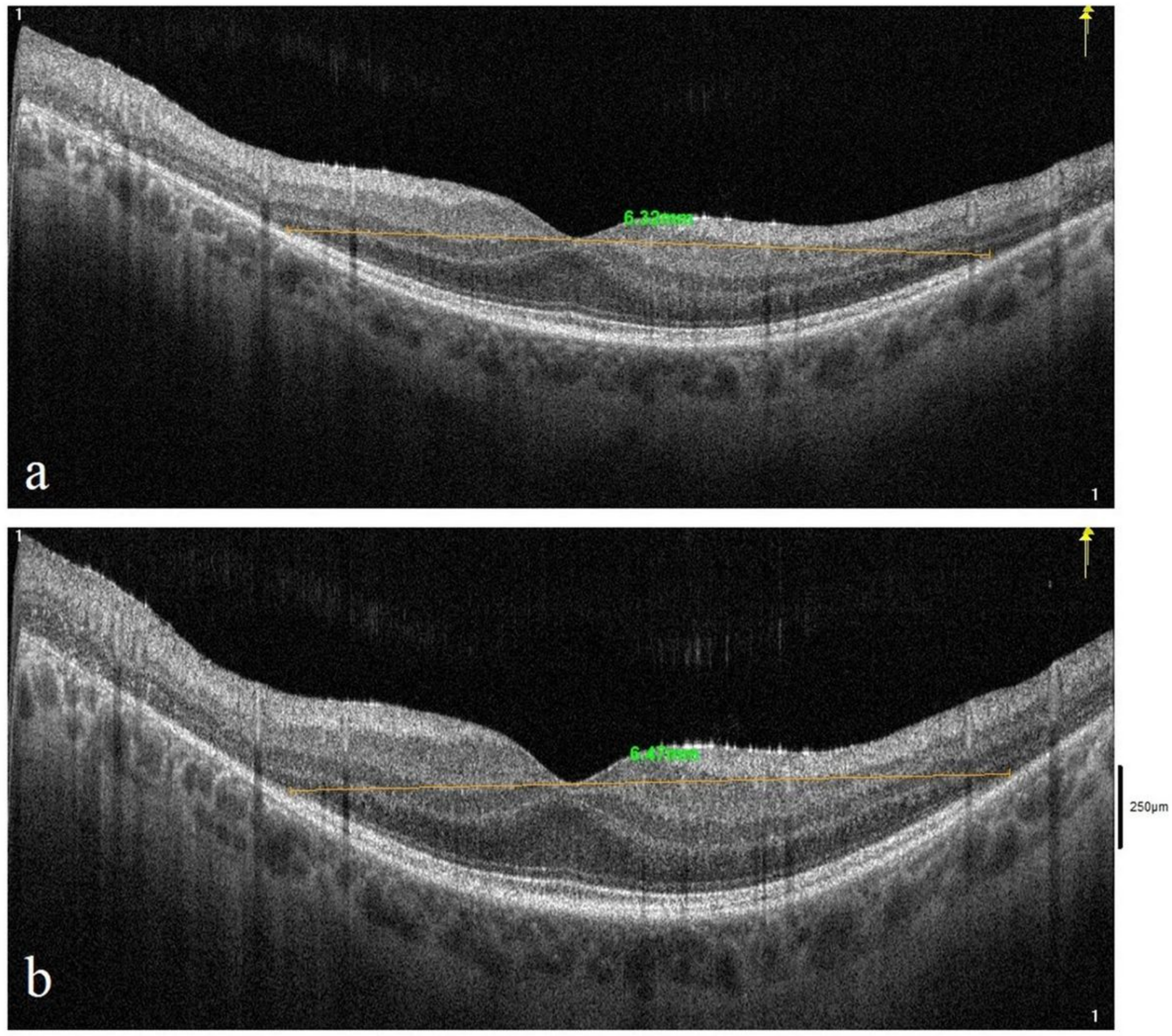

Figure 6

Vertical EZWs of the retinitis pigmentosa patient receiving only aPRP. (Table 2 Patient no. 1). a: Before treatment: $6.32 \mathrm{~mm}$ b: The 13th month of follow-up post-treatment: $6.47 \mathrm{~mm}$. 


\begin{tabular}{|c|c|c|c|c|c|c|c|c|c|}
\hline $1980 / 08 / 03$ & & & & OS & $1980 / 08 / 03$ & & & & OS \\
\hline Dete: 20180803 & False NEG:Os & & Duration: 0932 & & Date: $2019 / 1221,13.25$ & False NEC:OH & & Duration: 1139 & \\
\hline Pattern: 242 & False POS:O\% & & Average pugil size: $3.8 \mathrm{~mm}$ & & Patten: 24.2 & False Pos: Oh & & Average pupil size: $3.8 \mathrm{~mm}$ & \\
\hline Strategy.zest & 65:014 & & Fover: $34 \mathrm{~dB}$ & & Strotegr.2est & BS:Q15 & & fover: $34 \mathrm{~dB}$ & \\
\hline
\end{tabular}
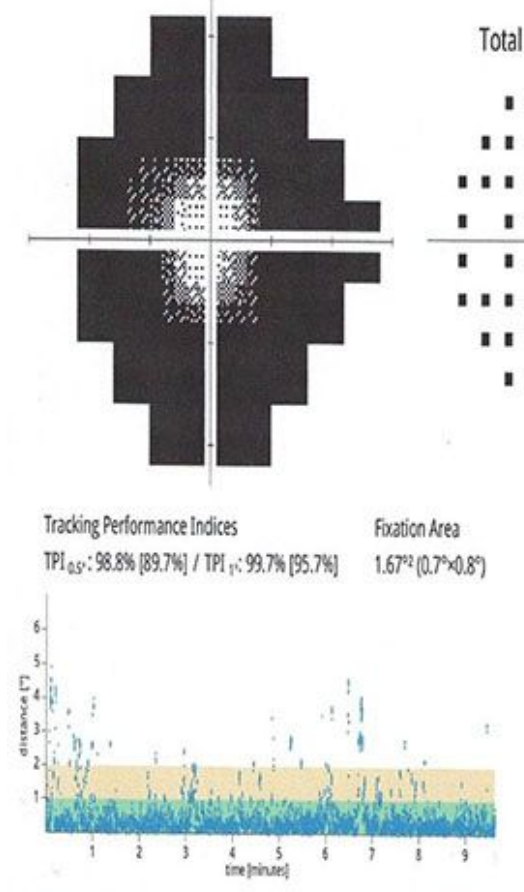

compass
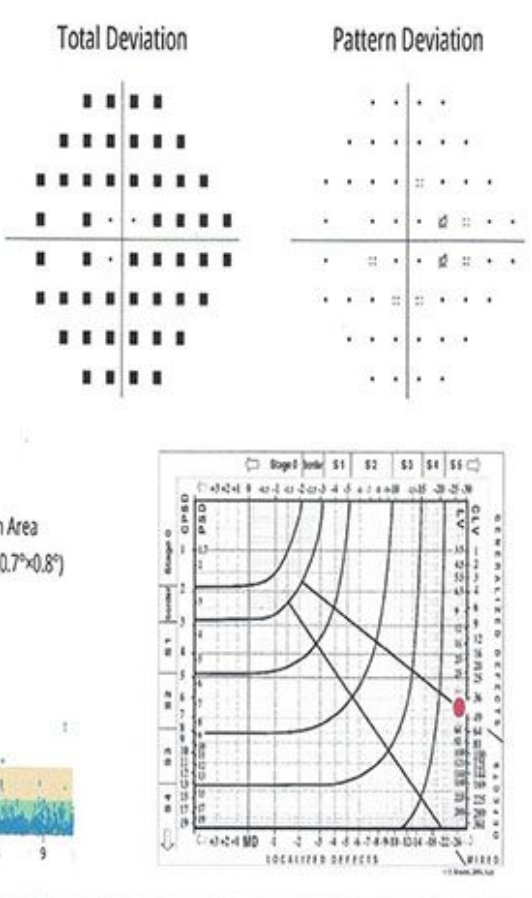

SN 00089, v25.1
8 center w
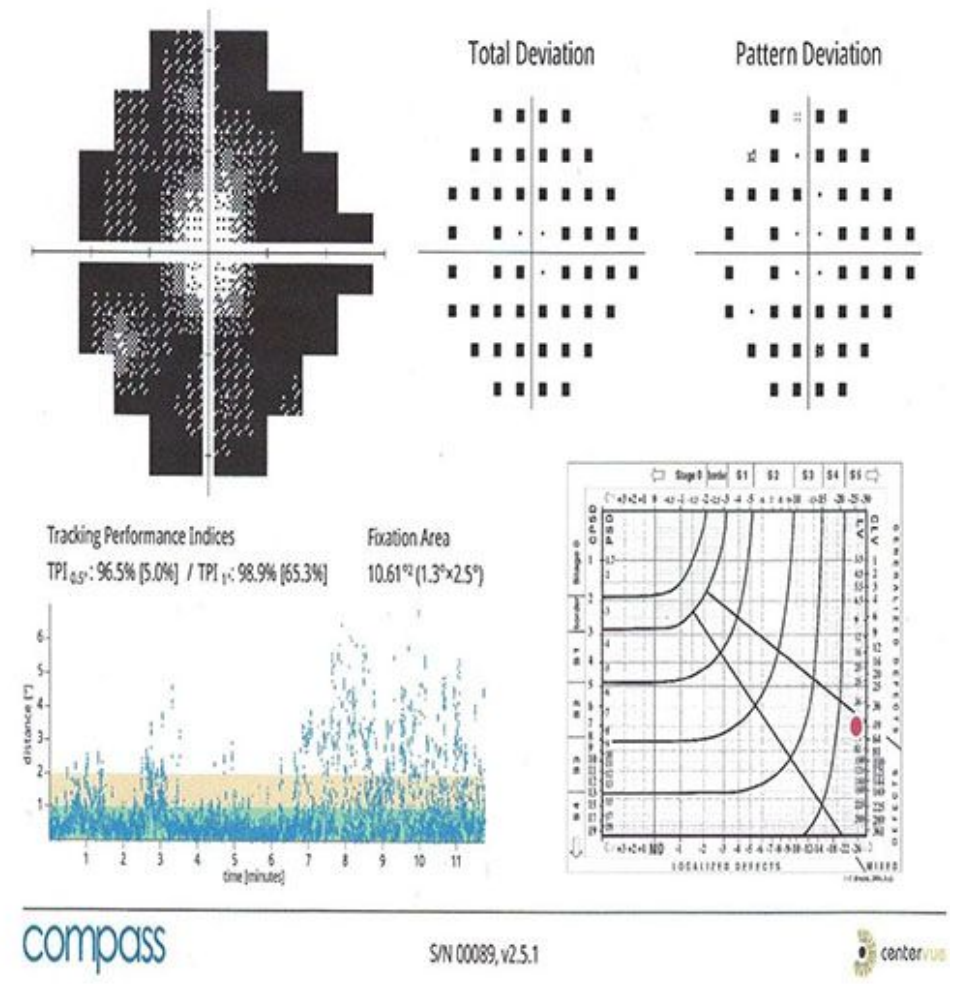

\section{Figure 7}

Visual field FPDI changes of the retinitis pigmentosa patient receiving only aPRP. (Table 2 Patient no. 1). a: Before treatment $24 \%$, b: The 13 th month of follow-up post-treatment: $28 \%$. 

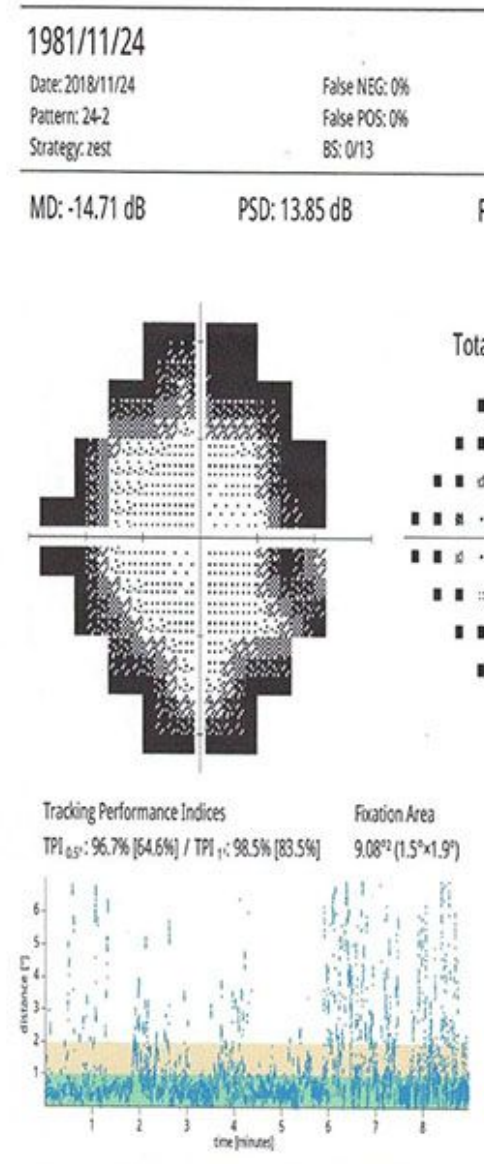

compass
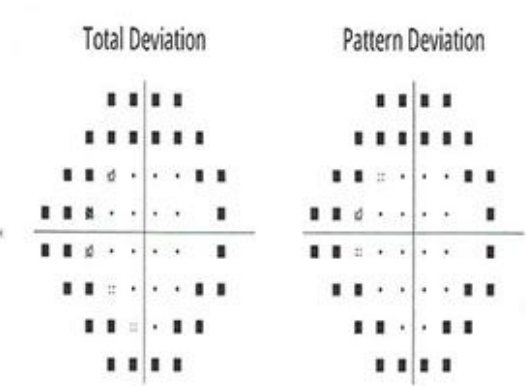

Glacooma Stoging Systen 2

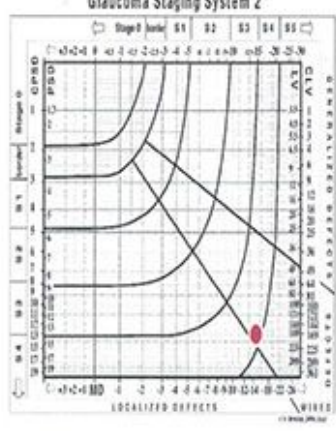

SN $00059,12.5 .1$
Durationc 0as2

Average pupi size. $40 \mathrm{~mm}$ Fover. $36 \mathrm{d8}$

Trading ON zestcc: ON

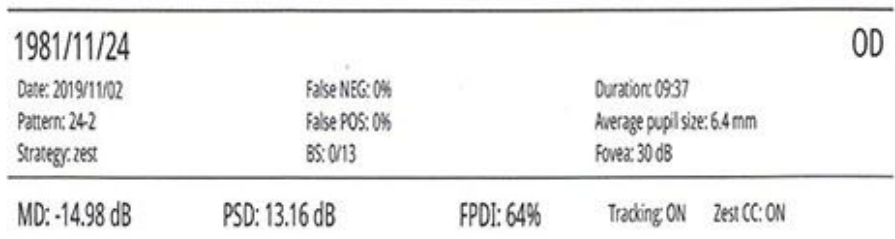
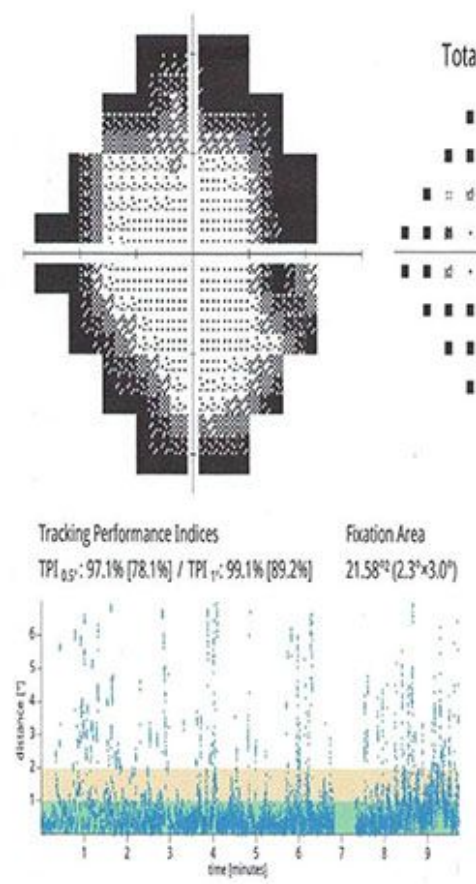

Total Deviation

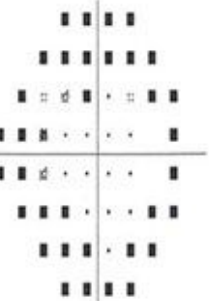

Pattern Deviation

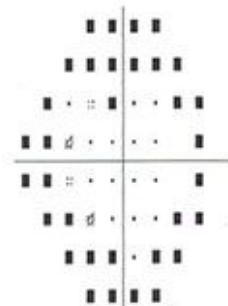

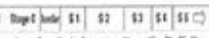

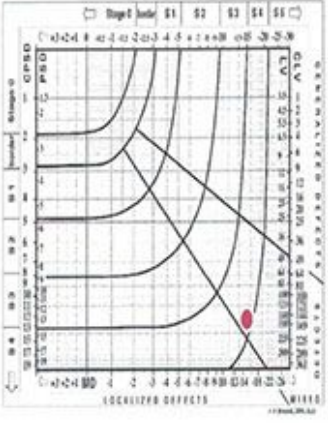

compass

SN $00089,125.1$

\section{Figure 8}

Visual field FPDI changes of the retinitis pigmentosa patient receiving only aPRP. (Table 2 Patient no. 2). a: Before treatment: $64 \%$ b: The 13 th month of follow-up post-treatment: $64 \%$. 


\section{Left / OS}
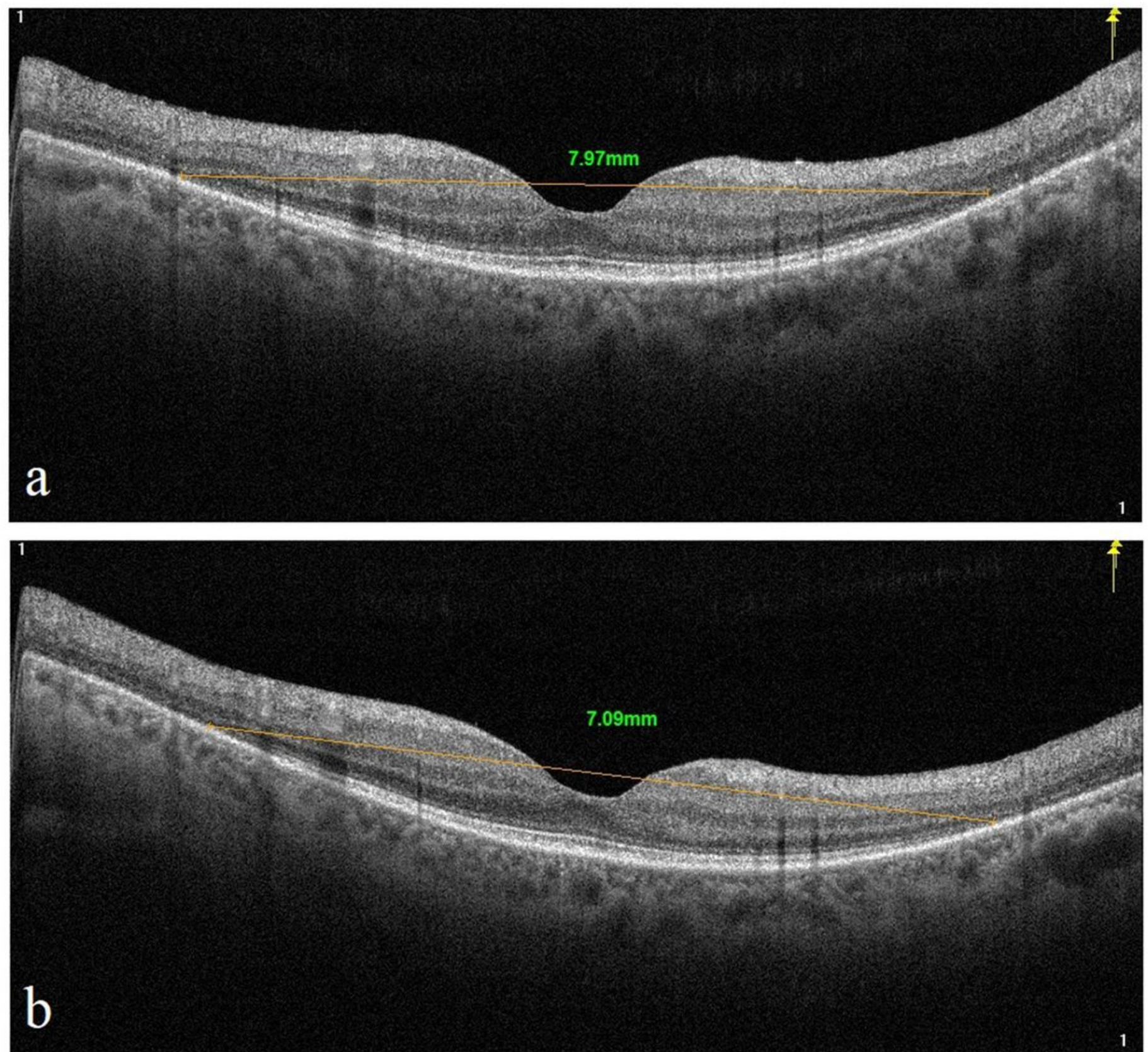

\section{Figure 9}

Vertical EZWs of the retinitis pigmentosa patient, natural course. (Table 3 Patient no. 1) a: Before treatment $7.97 \mathrm{~mm}$ b: The 13th month of follow-up post-treatment: $7.09 \mathrm{~mm}$. 


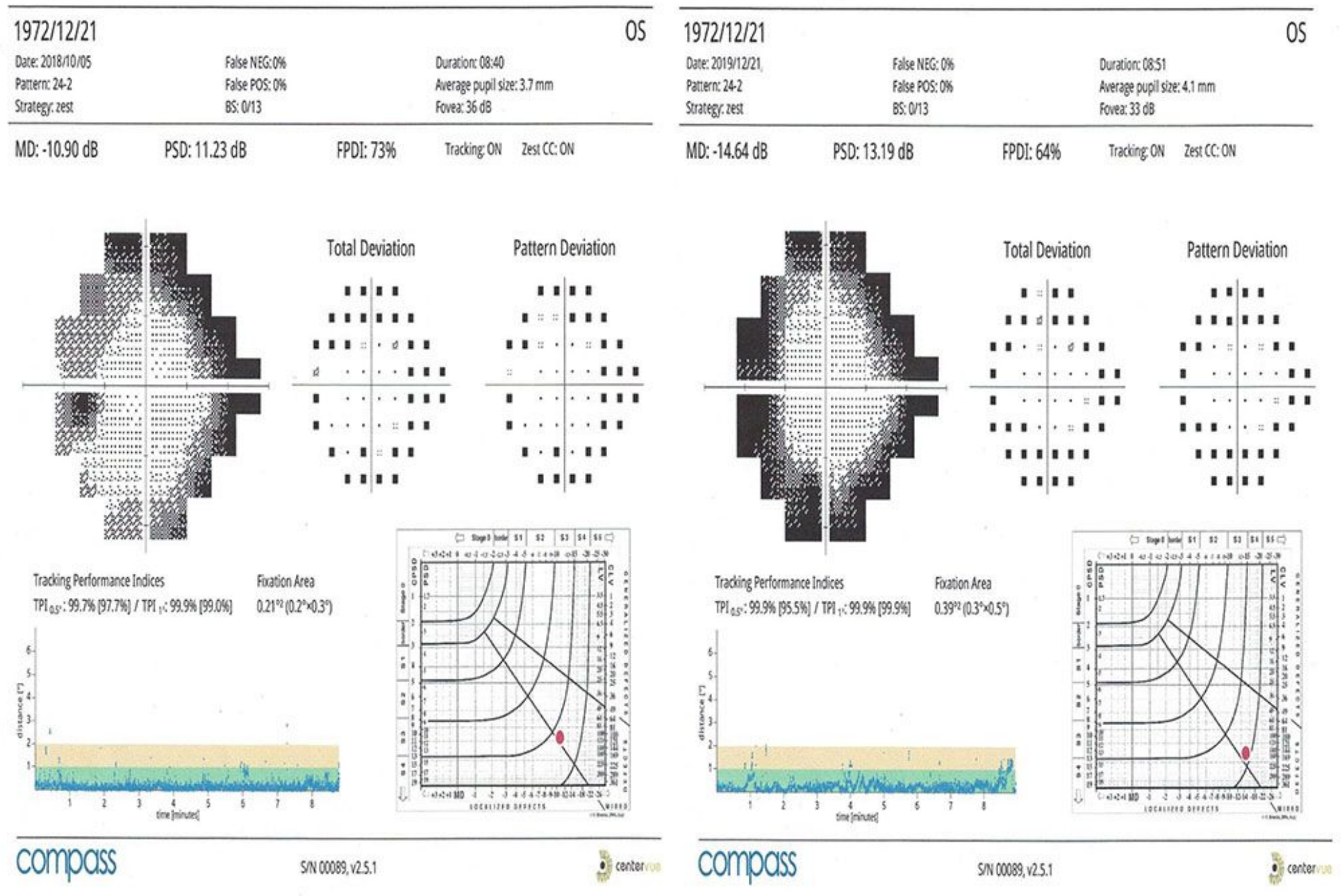

\section{Figure 10}

Visual field FPDI changes of the retinitis pigmentosa patient, natural course. (Table 3 Patient no .1) a: Before treatment $73 \% \mathrm{~b}$ : The 13th month of follow-up post-treatment: $64 \%$.

\section{Supplementary Files}

This is a list of supplementary files associated with this preprint. Click to download.

- Tables14.pdf 